\title{
Stimulus-driven attentional capture by equiluminant color change
}

\author{
SHENA LU and KE ZHOU \\ Key Laboratory of Cognitive Science, Graduate School and Institute of Biophysics, \\ Chinese Academy of Sciences, Beijing, China
}

\begin{abstract}
The aim of this research was to investigate the mechanisms underlying stimulus-driven attentional capture by feature changes in basic dimensions, and we chose color for the present investigation. In Experiment 1, participants searched for a target letter among colored disks containing distractor letters while a disk underwent color change. Although color change was irrelevant to the task and uninformative about the target position, we found a strong form of stimulus-driven attentional capture. Experiment 2 demonstrated that salient color discontinuity per se could not capture attention, ruling out the possibility that the capture effect we observed might be due to color discontinuity. In Experiment 3, we observed the capture effect by color change again in a more optimized experimental design. The present findings show that color change captures attention, supporting our view that dynamic feature changes can capture attention in a stimulus-driven manner.
\end{abstract}

Visual selective attention is currently thought to be controlled by two distinct mechanisms. On the one hand, selection is thought to occur in a goal-directed manner when attention is allocated to objects and events that are consistent with the current behavioral goals or intentions of the observer. On the other hand, selection is thought to occur in a stimulus-driven manner when attention is involuntarily drawn to objects and events that are irrelevant to the current goals or intentions of the observer. The phenomenon of stimulus-driven attentional selection is also referred to as attentional capture (for reviews, see Theeuwes, 1994, and Yantis, 2000).

Attentional capture is important because it suggests that attentional shift can be automatically driven by some stimulus properties, which may be fundamental for visual information processing. However, there has been relatively little evidence provided in support of this pure form of stimulus-driven attentional control. Although contemporary models of visual search predict that salient feature singletons should be able to attract attention automatically (Cave \& Wolfe, 1990; Duncan \& Humphreys, 1989; Wolfe, 1994), this issue is quite controversial. Some studies have shown that feature singletons in color, luminance, or motion fail to elicit attentional capture effects in the absence of any goal-directed prioriti-

This research was supported by National Natural Science Foundation of China Grant 697900800, Ministry of Science and Technology of China Grant 2002CCA01000, and Chinese Academy of Sciences Grant KGCX2-SW-101. The authors are grateful to Jan Theeuwes and two anonymous reviewers for helpful comments on the manuscript. Special thanks are owed to Daniel J. Simons for his valuable suggestion in preparing the manuscript and Anne P. Hillstrom for her kindness in improving our English. Correspondence should be addressed to S. Lu, Key Laboratory of Cognitive Science, Graduate School and Institute of Biophysics, Chinese Academy of Sciences, 15 Datun Road, Beijing 100101, China (e-mail: 1sn@cogsci.ibp.ac.cn). zation (Hillstrom \& Yantis, 1994; Jonides \& Yantis, 1988; Todd \& Kramer, 1994). Some studies have shown that feature singletons are able to capture attention only when they match the contingent attentional control setting for that feature (Folk, Remington, \& Johnston, 1992; Folk, Remington, \& Wright, 1994) - that is, not in a purely stimulus-driven way. Other recent studies have demonstrated the capture effect by using indirect methods that reasonably exclude top-down influences (Horstmann, 2002; Scholl, 2000; Turatto \& Galfano, 2001). Until now, the most well-established source of evidence for stimulusdriven attentional capture has involved studies showing that the abrupt onset of a new perceptual object captures attention in a stimulus-driven fashion (Jonides \& Yantis, 1988; Yantis \& Hillstrom, 1994; Yantis \& Jonides, 1984), even though the capture effect by abrupt onset can be modulated by top-down factors (Folk et al., 1992; Gibson \& Kelsey, 1998; Yantis \& Jonides, 1990). Moreover, other recent studies have shown that some stimulus properties also appear to capture attention in a stimulus-driven way, such as sudden motion (Abrams \& Christ, 2003; Franconeri \& Simons, 2003; Hillstrom \& Yantis, 1994) and looming (Franconeri \& Simons, 2003).

In summary, most current evidence for stimulus-driven attentional capture is unique to some dynamic events. Although the question of whether static discontinuities in some basic feature dimensions capture attention remains inconclusive, we propose that dynamic feature changes in basic dimensions should attract attention involuntarily. Intuitively, it seems quite reasonable to suspect that feature changes might be especially noticeable. When a sudden feature change of an object occurs, it might be behaviorally urgent and require immediate action independently of the observer's current behavior, thereby capturing attention. Sensitivity to feature changes in the environment may help organisms deal with urgent events for survival. 


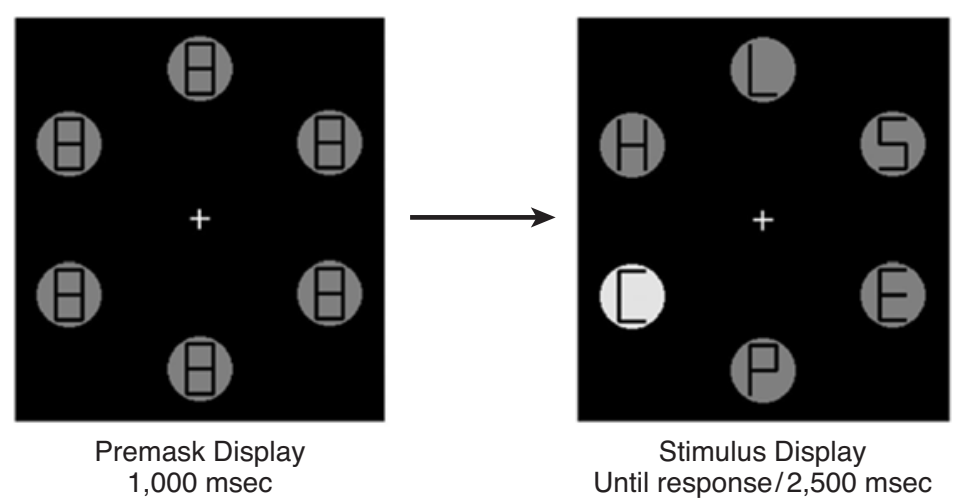

Figure 1. Sequence of events for a typical trial in Experiment 1 (display size is six in this example). The premask display was visible for $1,000 \mathrm{msec}$ prior to the stimulus display, at which point one of the colored disks changed into an equiluminant contrary-colored disk, constituting the color-changed item. Differences in color are illustrated as differences in gray level (for example, bright gray corresponds to green and dark gray corresponds to red, or vice versa). At the same time, black block figure eights changed into letters to be searched. The participants' task was to search for the target letter $S$. The location of the target letter was uncorrelated with the occurrence of color change. In this example, the target letter is not presented inside the color-changed item.

In the present study, we chose feature change in the color dimension for our initial investigation. Although many recent studies have already addressed the question of whether color change can capture attention involuntarily, this issue is still under debate. Some studies have shown that equiluminant color change cues could guide attention somewhat in the cue-target paradigm (Lambert, Wells, \& Kean, 2003; Snowden, 2002). Theeuwes (1990, 1995) found that equiluminant color changes could not capture attention, whereas Gellatly, Cole, and Blurton's (1999) Experiment 2 showed that equiluminant color changes were indeed capable of capturing attention.

To establish whether color change can grab attention in a real stimulus-driven fashion, the first step is to rule out any top-down effects, including the potential influence of goal and search strategies. In our first experiment, we used the irrelevant feature search paradigm, as in Jonides and Yantis's (1988) experiments (see also Simons, 2000). Participants searched for a prespecified target letter in a search display in which an element underwent a sudden color change. Color change was orthogonal to the participants' adopted attentional setting for letter identity and was uninformative about target position. Thereby, there was no incentive for the participants to deliberately attend to color change. If the irrelevant colorchanged item could capture attention in a stimulus-driven fashion, reaction time (RT) should be facilitated when the target happened to be the color-changed item.

\section{EXPERIMENT 1}

\section{Method}

Participants. Ten undergraduates served as paid volunteers. All had normal or corrected-to-normal vision.

Stimuli and Procedure. The trial events are shown in Figure 1. Each trial began with a premask display that contained a central fix- ation cross and three or six placeholder stimuli. Each placeholder was a colored disk element $\left(1.2^{\circ}\right.$ in radius from a viewing distance of $57 \mathrm{~cm})$ containing a black block figure eight $\left(1.9^{\circ} \times 1.0^{\circ}\right)$. The placeholders were equally spaced around the fixation cross on an imaginary circle $\left(5.7^{\circ}\right.$ in radius). The three placeholders formed an upward-pointing equilateral triangle; the six placeholders formed a hexagon. All the placeholders were either green (CIE $x, y$ chromaticity coordinates of .284/.606) or red (CIE $x, y$ chromaticity coordinates of .628/.345), which were matched for luminance $\left(6.5 \mathrm{~cd} / \mathrm{m}^{2}\right)$. After a $1,000-\mathrm{msec}$ premask display, the stimulus display was presented. At the end of the 1,000 -msec premask period, elements of each figure eight were extinguished to reveal letters abruptly. The target letter was S, whereas the population of distractor letters was H, U, P, E, F, C, and L. At the same time that the letters were presented, one of the colored disks changed color abruptly, while the color of all other disks remained unchanged. Thus, the stimulus display always contained one red disk among green disks or one green disk among red disks. Half of the trials in each block had a red singleton, and the other half had a green singleton. The order was random. The stimulus display remained present until a response was given or for $2,500 \mathrm{msec}$ if no response was made.

The participants' task was to search for the target letter $\mathrm{S}$ in the stimulus display. They responded by pressing one of two keys ("m" or "c") for target present/absent (the responses of hands were counterbalanced across participants). Immediate error feedback was provided by a $200-\mathrm{msec}, 400-\mathrm{Hz}$ beep. RTs were measured from the onset of the stimulus display. The participants were instructed to maintain fixation throughout the entire trial and to respond as quickly as possible while maintaining accuracy. They were also informed that the target position was random and that the location of the color-changed disk was uninformative about the target position.

Design. Two main variables, display size and trial type, were completely crossed. The two display sizes were 3 and 6 , with equal numbers of trials in each block. The three trial types were target present within the disk whose color was changed (or for brevity, positive unique), target present within another disk whose color remained (or positive no-unique), and target absent (or negative). In each block, positive unique, positive no-unique, and negative trials were combined with the two display size conditions. The target was present on one half of the trials in each block. When the target was present, it had an equal chance of appearing within any of the place- 
holder disks, so that the occurrence of color change was uncorrelated with the occurrence of the target. For example, when the display size was three, one third of the positive trials were unique. After a practice block of 25 trials, each participant completed three 120 -trial blocks - that is, a total of 360 observations. They were given a short rest after each block. The experimental session lasted approximately $1 \mathrm{~h}$, including breaks.

\section{Results and Discussion}

In this and the subsequent experiments, correct RTs greater than $300 \mathrm{msec}$ and less than 2,000 msec were submitted to analysis. This resulted in the removal of approximately $2.3 \%$ of all the trials. The error rates in all the conditions are shown in Table 1.

Mean RTs as a function of display size and trial type are shown in Figure 2. Of most interest was the difference between the two target-present functions. Therefore, these data were entered into a two-way repeated measures analysis of variance (ANOVA), which yielded significant main effects of both display size $[F(1,9)=$ $21.34, p<.002]$ and target type $[F(1,9)=29.69, p<$ $.001]$. The interaction between the two variables was also significant $[F(1,9)=14.05, p<.006]$, indicating that there was a difference between the slopes of the two targetpresent functions. Furthermore, the slope of the positive unique function was $3.7 \mathrm{msec} / \mathrm{item}$, which was not significantly greater than zero $[t(9)=1.36, p>.200]$, indicating efficient search of this function. The slope of the positive no-unique function was $27.2 \mathrm{msec} /$ item.

The results of Experiment 1 indicated that when the target was located inside the color-changed item, RT was rapid and was influenced little by display size, providing evidence that the color-changed item clearly received high priority in the present visual search task, despite the fact that it did not predict the target position. Since the experimental design reasonably excluded any incentive for the participants to attend to the color-changed item, it seems reasonable to suggest that color change can summon an attentional shift in a stimulus-driven fashion. However, another possible explanation of the results of Experiment 1 is that the capture effect that we observed may have been due to static color discontinuity in the stimulus display, rather than to dynamic color change. To test this possibility, we conducted a control experiment in which only the stimulus display was presented, so that there was no occurrence of color change.

Table 1

Error Rates (in Percentages) by Display Size and Trial Type in Experiment 1

\begin{tabular}{lcc}
\hline & \multicolumn{2}{c}{ Display Size } \\
\cline { 2 - 3 } Trial Type & 3 & 6 \\
\hline Positive unique & 2.0 & 4.7 \\
Positive no-unique & 2.0 & 4.4 \\
Negative & 1.7 & 1.2 \\
\hline
\end{tabular}

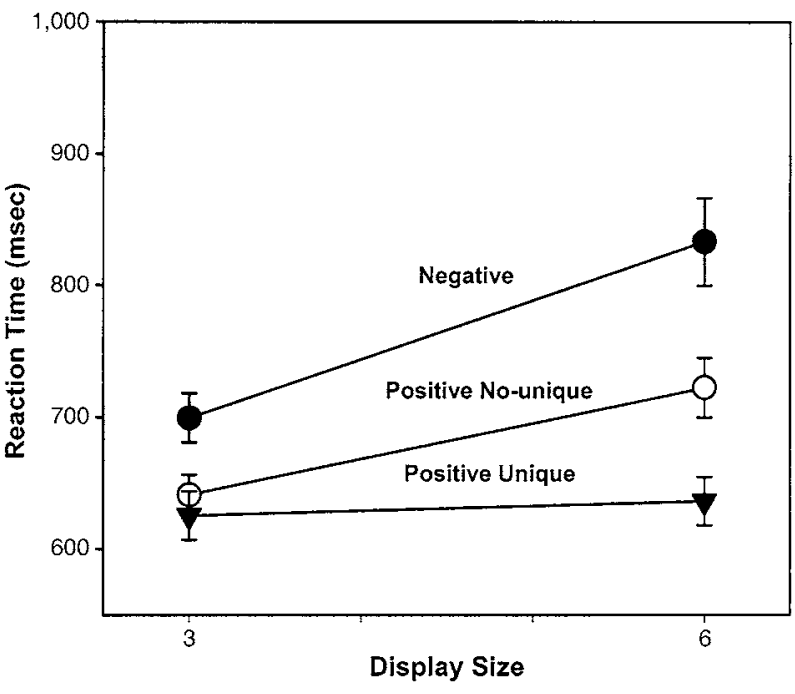

Figure 2. Mean reaction times in Experiment 1, plotted as a function of display size for target negative, target positive nounique, and target positive unique trials.

\section{EXPERIMENT 2}

\section{Method}

Participants. Ten undergraduates served as paid volunteers. All had normal or corrected-to-normal vision.

Stimuli, Procedure, and Design. This experiment was similar to Experiment 1, except that only the stimulus display was presented. No premasks were used, so that no color change occurred. The three trial types were target present within the color singleton disk (or for brevity, positive unique), target present within another nonsingleton disk (or positive no-unique), and target absent (or negative).

\section{Results and Discussion}

In this experiment, approximately $1.6 \%$ of all the trials were discarded. The error rates in all conditions are shown in Table 2.

Mean RTs are shown in Figure 3. The data for the two target-present functions were subjected to an ANOVA, which revealed a significant main effect of display size $[F(1,9)=41.34, p<.001]$ but no effect of target type $[F(1,9)=1.17, p>.30]$. The interaction was significant $[F(1,9)=13.11, p<.007]$, suggesting that the color singleton item enjoyed a real, but small, priority advantage, relative to nonsingleton items. However, according to the prediction of the attentional capture hypothesis, the function when the target happens to be the singleton should have a zero slope and be substantially faster than when the target is one of the nonsingleton elements. In fact, the slope of the positive unique function was $22.3 \mathrm{msec} /$ item, which was significantly greater than zero $[t(9)=4.98$, $p<.002]$. The slope of the positive no-unique function was $30.5 \mathrm{msec} /$ item. We did not observe strong evidence of attentional capture in Experiment 2, so we reject the possibility that in Experiment 1, attention was captured by static color discontinuity. 
Table 2

Error Rates (in Percentages) by Display Size and Trial Type in Experiment 2

\begin{tabular}{lcc}
\multicolumn{2}{c}{ Trial Type in Experiment 2 } \\
\cline { 2 - 3 } Trial Type & 3 & \multicolumn{2}{c}{ Display Size } \\
\cline { 2 - 3 } \multicolumn{1}{c}{} & 2.0 & 1.3 \\
Positive unique & 1.7 & 3.2 \\
Positive no-unique & 0.8 & 1.0 \\
Negative &
\end{tabular}

\section{EXPERIMENT 3}

Experiment 2 showed that the color singleton had a small priority for attentional capture, suggesting that the attentional capture effect in Experiment 1 was not due mainly to static color discontinuity and might be due to dynamic color change. To examine this suggestion further, we ran the present experiment, in which there was no distinctive color singleton, so that the effect of color change was isolated. Moreover, we matched the stimuli for perceptual luminance, instead of physical luminance, excluding the possible contribution of subjective luminance change.

\section{Method \\ Participants. Ten undergraduates served as paid volunteers. All had normal or corrected-to-normal vision. \\ Stimuli. This experiment was similar to Experiment 1. But un- like Experiment 1, in which only two kinds of color (red and green) were used, four kinds of color (red, green, blue, and yellow) were used in both the premask display and the stimulus display. The four colors were matched for perceptual luminance for each participant. In the premask display, each disk possessed any of the four colors. When the stimulus display was presented, the color of one disk was changed, while the colors of the other disks remained unchanged. When the display size was three, three of the four colors were cho- sen randomly to be used in the premask display, and the color- changed disk possessed the fourth color in the stimulus display; when the display size was six, all four colors were used in both dis- plays, with the constraint that each color was used no more than twice in each display. This design ensured that the target was not a color singleton amid homogeneous distractors. \\ Procedure and Design. The procedure and design were similar to those in Experiment 1, except that before the experimental ses- sion, each participant performed a luminance-matching test to equate the perceptual luminance of the four colors. Luminance matching was carried out using a variation of the flicker photometry technique. The participants viewed two colored patches (a disk element with $7.5^{\circ}$ of radius) that alternated in the center of the screen at a frequency of $60 \mathrm{~Hz}$. While the luminance of one colored patch remained con- stant, the participants adjusted the luminance of the other colored patch by pressing one of two keys to dim or brighten it until they found the luminance level that produced the minimum flicker. The four colors matched each other. The final luminance of each color for each participant was applied to the respective experimental session.}

\section{Results and Discussion}

In this experiment, approximately $1.3 \%$ of all the trials were discarded. The error rates in all the conditions are shown in Table 3 .

Mean RTs are shown in Figure 4. The data of two targetpresent functions were subjected to an ANOVA, which revealed significant main effects of both display size
$[F(1,9)=6.65, p<.030]$ and target type $[F(1,9)=$ $13.64, p<.006]$. The interaction was significant as well $[F(1,9)=14.17, p<.005]$, indicating that there was a difference between the slopes of the two target-present functions. Furthermore, the slope of the positive unique function was $6.2 \mathrm{msec} /$ item, which was not significantly greater than zero $[t(9)=0.96, p>.360]$, indicating efficient search of this function. The slope of the positive no-unique function was $20.8 \mathrm{msec} /$ item. Even under the condition that the target was not a distinctive singleton and the stimuli were perceptually equiluminant, we observed reliable evidence of attentional capture again, providing further evidence that the capture effect in Experiment 1 was due to color change.

\section{GENERAL DISCUSSION}

Stimulus-driven attentional capture refers to an attentional control mechanism in which visual objects and events receive high attentional priority independently of the current behavioral goals. Despite its importance, there has been relatively little evidence offered in support of this form of attentional control. Previous studies have shown that only some dynamic events, such as abrupt onset, appear to capture attention consistently.

In the present study, we suggest that dynamic feature changes in basic feature dimensions should capture attention involuntarily, and we chose the color dimension for our initial investigation. Experiment 1 showed that the color-changed item enjoyed high priority in visual search, despite the fact that it was neither relevant to the task nor predictive of the target position, exemplifying a strong form of attentional capture. Experiment 2 showed that a color singleton per se possessed weak ability to capture attention, ruling out the possibility that the capture effect we observed in Experiment 1 was due mainly

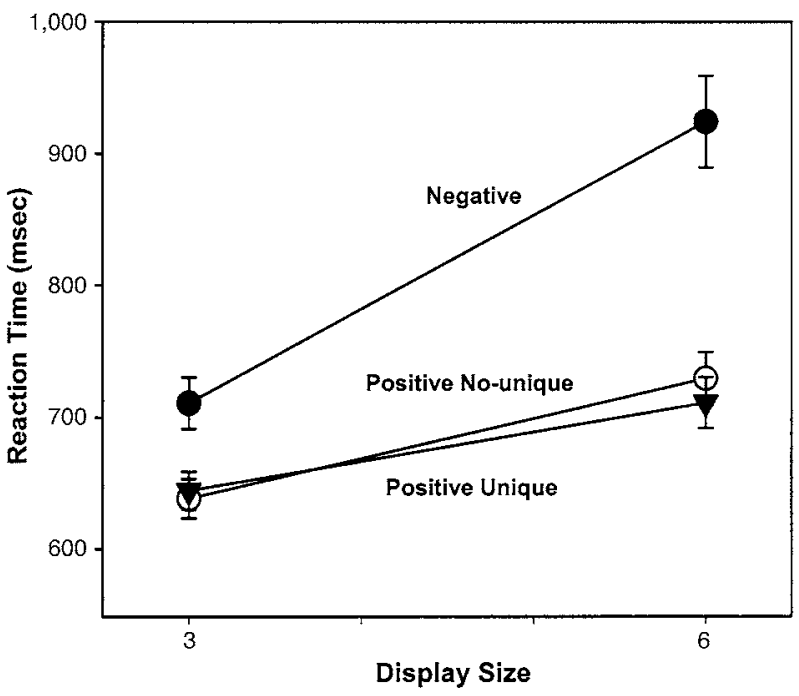

Figure 3. Mean reaction times in Experiment 2, plotted as a function of display size for target negative, target positive nounique, and target positive unique trials. 
Table 3

Error Rates (in Percentages) by Display Size and Trial Type in Experiment 3

\begin{tabular}{lcc}
\multicolumn{2}{c}{ Trial Type in Experiment 3 } \\
\hline Trial Type & 3 & 6 \\
\cline { 2 - 3 } & 2.7 & 2.0 \\
\hline Positive unique & 1.0 & 2.0 \\
Positive no-unique & 1.0 & 0.7 \\
Negative &
\end{tabular}

to color discontinuity. In Experiment 3, we used a perceptually equiluminant multiple-color design, so that the effect of color change was isolated, and found a reliable attentional capture effect again. The three experiments together demonstrate that color change elicits a real stimulus-driven attentional capture without any relevant attentional setting.

The present results do not corroborate Theeuwes's (1990, 1995) findings suggesting that equiluminant color changes cannot capture attention, and we reason that this discrepancy might be due to procedural differences. In Theeuwes's (1990) Experiment 4, the uniquely colored surround was changed into a nonuniquely colored surround $260 \mathrm{msec}$ after stimulus presentation. The colorchanged item failed to capture attention. Furthermore, in Theeuwes's (1995) experiments, the participants viewed multiple outline circles presented on an equiluminant background. After 50 or $100 \mathrm{msec}$, an identical circle was added to the display. The new circle failed to pop out even when the participants were set to detect it. There were, however, various differences between the procedures used by Theeuwes $(1990,1995)$ and the present one. First, all the stimuli in Theeuwes's experiments were defined by outline surrounds, rather than by solid disks as in the present experiments, making color change relatively inconspicuous. Thus, the potential of color change to capture attention might have been relatively weak. Second, as Gellatly et al. (1999) pointed out, because of the coarse temporal resolution of the chrominance channel, the visual system might have failed to effectively segregate the relatively inconspicuous color change from the unchanged distractors during the short interval between two stimulus displays $(260 \mathrm{msec}$ for Theeuwes, 1990 - especially, 50 or $100 \mathrm{msec}$ for Theeuwes, 1995). Thus, the potential rendered by color change may not have been powerful enough to capture attention in Theeuwes's $(1990,1995)$ experiments. Using relatively larger stimuli and a longer interval, as in the present experiments, Gellatly et al. (1999, Experiment 2) did find a reliable capture effect by an abrupt onset defined by color change. Likewise, the present study provides evidence of attentional capture by color change in an existing object.

The present study provides direct behavioral evidence supporting our suggestion that dynamic feature changes in basic dimensions could capture attention in a stimulusdriven way. Feature changes in an existing object might have an impact on the distribution of attention because feature changes might have high ecological significance. The visual system may have evolved so as to be sensitive to changes in object properties, because changes reveal new information about the visual environment. For instance, in nature, organisms need to maintain a high sensitivity to environmental changes for survival, because environmental changes may indicate the possible appearance of predators or prey. If a change occurs, whatever the organism is doing, the visual system should allocate a portion of attentional resources to process the change information and to make a response accordingly.

The present findings are incompatible with the prediction of the contingent involuntary orienting hypothesis that attentional capture is always conditional on the observer's intention (Folk et al., 1992). However, our suggestion itself provides a necessary complement to this model of attentional capture. Besides what organisms intend to see, they also should perceive other unintentional events, such as unexpected environmental changes that signal surprise events or danger. However, our findings agree with Yantis and Hillstrom's (1994) new object hypothesis in a broad sense, according to which only new objects capture attention unintentionally. Although we did not determine whether feature change in color in our experiments caused the appearance of a new perceptual object, color change actually caused segregation of an element from its background and thereby captured attention (Hillstrom \& Yantis, 1994). Actually, the appearance of a new perceptual object can be seen as an aggregation of feature changes, because a new object introduces a variety of new features at once. Moreover, our findings are in broad agreement with the behavioral urgency hypothesis (Franconeri \& Simons, 2003) that urgent events can capture attention. These researchers found that dynamic moving and loom-

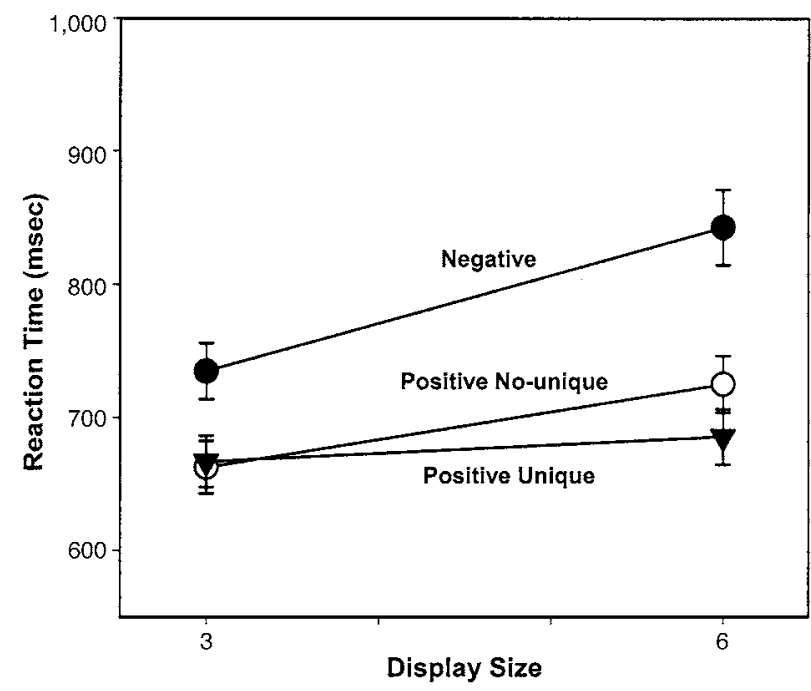

Figure 4. Mean reaction times in Experiment 3, plotted as a function of display size for target negative, target positive nounique, and target positive unique trials. 
ing stimuli that signaled potentially behaviorally urgent events captured attention, whereas other dynamic events, such as receding stimuli that were not as likely to be urgent, did not capture. However, how are we to define $u r$ gent? We contend that, in Franconeri and Simons's findings, urgent events can be considered as feature changes in nature. That is, in their experiments, moving stimuli could be considered to be changes from a static state to a dynamic state, and looming stimuli could be considered to be changes in size or depth. Although the failure with receding stimuli, which could also be seen as dynamic feature changes, appears to be incompatible with our suggestion that dynamic feature changes can capture attention in a stimulus-driven fashion, it is possible to imagine that our suggestion can account for most findings in attentional capture. Besides the findings of attentional capture above, other recent studies support our suggestion as well. For instance, sudden motion (Abrams \& Christ, 2003; Hillstrom \& Yantis, 1994), unexpected color change (Horstmann, 2002), and luminance contrast change paired with contrast polarity change (Enns, Austen, Di Lollo, Rauschenberger, \& Yantis, 2001) actually capture attention in a strongly stimulus-driven manner.

\section{REFERENCES}

Abrams, R. A., \& Christ, S. E. (2003). Motion onset captures attention. Psychological Science, 14, 427-432.

CAVE, K. R., \& Wolfe, J. M. (1990). Modeling the role of parallel processing in visual search. Cognitive Psychology, 22, 225-271.

DunCan, J., \& HumphreYs, G. W. (1989). Visual search and stimulus similarity. Psychological Review, 96, 433-458.

Enns, J. T., Austen, E. L., Di Lollo, V., Rauschenberger, R., \& YANTIS, S. (2001). New objects dominate luminance transients in setting attentional priority. Journal of Experimental Psychology: Human Perception \& Performance, 27, 1287-1302.

Folk, C. L., Remington, R. W., \& Johnston, J. C. (1992). Involuntary covert orienting is contingent on attentional control settings. Journal of Experimental Psychology: Human Perception \& Performance, 18, 1030-1044.

Folk, C. L., Remington, R. W., \& Wright, J. H. (1994). The structure of attentional control: Contingent attentional capture by apparent motion, abrupt onset, and color. Journal of Experimental Psychology: Human Perception \& Performance, 20, 317-329.

Franconeri, S. L., \& Simons, D. J. (2003). Moving and looming stimuli capture attention. Perception \& Psychophysics, 65, 999-1010.
Gellatly, A., Cole, G., \& Blurton, A. (1999). Do equiluminant object onsets capture visual attention? Journal of Experimental Psychology: Human Perception \& Performance, 25, 1609-1624.

Gibson, B. S., \& Kelsey, E. M. (1998). Stimulus-driven attentional capture is contingent on attentional set for displaywide visual features. Journal of Experimental Psychology: Human Perception \& Performance, 24, 699-706.

Hillstrom, A. P., \& Yantis, S. (1994). Visual motion and attentional capture. Perception \& Psychophysics, 55, 399-411.

Horstmann, G. (2002). Evidence for attentional capture by a surprising color singleton in visual search. Psychological Science, 13, 499-505.

JoNIDES, J., \& YANTIS, S. (1988). Uniqueness of abrupt visual onset in capturing attention. Perception \& Psychophysics, 43, 346-354.

Lambert, A., Wells, I., \& Kean, M. (2003). Do isoluminant color changes capture attention? Perception \& Psychophysics, 65, 495-507.

SCHOLL, B. J. (2000). Attenuated change blindness for exogenously attended items in a flicker paradigm. Visual Cognition, 7, 377-396.

Simons, D. J. (2000). Attentional capture and inattentional blindness. Trends in Cognitive Sciences, 4, 147-155.

SNOWDEN, R. J. (2002). Visual attention to color: Parvocellular guidance of attentional resources? Psychological Science, 13, 180-184.

Theeuwes, J. (1990). Perceptual selectivity is task dependent: Evidence from selective search. Acta Psychologica, 74, 81-99.

Theeuwes, J. (1994). Endogenous and exogenous control of visual selection. Perception, 23, 429-440.

TheEuwes, J. (1995). Abrupt luminance change pops out; abrupt color change does not. Perception \& Psychophysics, 57, 637-644.

Todd, S., \& Kramer, A. F. (1994). Attentional misguidance in visual search. Perception \& Psychophysics, 56, 198-210.

Turatto, M., \& Galfano, G. (2001). Attentional capture by color without any relevant attentional set. Perception \& Psychophysics, 63, 286-297.

WoLfe, J. M. (1994). Guided Search 2.0: A revised model of visual search. Psychonomic Bulletin \& Review, 1, 202-238.

YANTIS, S. (2000). Goal-directed and stimulus-driven determinants of attentional control. In S. Monsell \& J. Driver (Eds.), Attention and performance XVIII: Control of cognitive processes (pp.71-104). Cambridge, MA: MIT Press.

YANTIS, S., \& Hillstrom, A.P. (1994). Stimulus-driven attentional capture: Evidence from equiluminant visual objects. Journal of Experimental Psychology: Human Perception \& Performance, 20, 95-107.

YANTIS, S., \& JoNIDES, J. (1984). Abrupt visual onsets and selective attention: Evidence from visual search. Journal of Experimental Psychology: Human Perception \& Performance, 10, 601-621.

YANTIS, S., \& JonIDES, J. (1990). Abrupt visual onsets and selective attention: Voluntary versus automatic allocation. Journal of Experimental Psychology: Human Perception \& Performance, 16, 121-134.

(Manuscript received March 30, 2004; revision accepted for publication September 25, 2004.) 